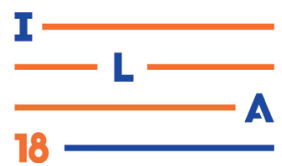

\title{
MÉTODOS E TÉCNICAS DE ESTUDOS EM WAYFINDING DE PESSOAS COM DEFICIÊNCIA EM UMA ETAPA PRÉ-DESIGN
}

\author{
METHODS AND TECHNIQUES IN WAYFINDING STUDIES OF \\ IMPAIRMENT PEOPLE IN A PRE DESIGN STAGE
}

\author{
Raphael Freitas Souza ${ }^{1}$, Mestrando \\ Solange Galvão Coutinho ${ }^{2}$, D. Sc. \\ Laura Bezerra Martins ${ }^{3}$, D. Sc.
}

(1) Universidade Federal de Pernambuco

e-mail: raphael.freitassouza@gmail.com

(2) Universidade Federal de Pernambuco

e-mail: sol2015ufpe@gmail.com

(3) Universidade Federal de Pernambuco

e-mail: bmartins.laura (a)gmail.com

\begin{abstract}
Palavras-chave: Wayfinding; Pessoas com Deficiência; Métodos e Técnicas
Diante do despreparo dos espaços para atender os deslocamentos das pessoas com deficiência, torna-se necessário identificar metodologias que investiguem suas reais necessidades. Obteve-se com esse estudo, através de Revisão da Literatura e Análise de Conteúdo, um mapeamento de metodologias, associando-as aos tipos de resultados que elas conseguiram proporcionar às pesquisas analisadas.
\end{abstract}

Key-words: Wayfinding; Impaired people; Methods and Techniques;

Due the unprepared spaces to attend the displacements of people with disabilities, it is necessary to identify methodologies that investigate their real needs. This study, through a Literature Review and a Content Analysis, obtained a mapping of methodologies, associating them with the types of results that were obtained with the analyzed researches.

\section{Introdução}

Os espaços urbanos são um emaranhado de estímulos visuais, sons, cheiros, movimentos, que se inter-relacionam em um constante processo de significação (KULAK, 2017). Percorrer, usufruir e se deslocar por esses espaços, passa a ser não só uma tarefa de caráter funcional, mas também rica em experiências sensoriais, estéticas e afetivas.

Dado isso, é fato que a diversidade sempre foi a principal marca da humanidade. Quando ela é bem compreendida e celebrada, há um grande ganho social e cultural, com o acolhimento pleno das diferenças individuais, incluindo as respectivas limitações (SIMÕES E BISPO, 2006). No entanto, quando se trata das pessoas com deficiência $(\mathrm{PcD})$ e mobilidade reduzida, suas necessidades físicas, psicológicas, cognitivas e afetivas muitas vezes não são plenamente atendidas pelo espaço urbano, uma vez que os projetos, incluindo aqueles ligados à mobilidade no contexto urbano, são focados em um ser humano hipotético, padrão, havendo pouco destaque para as diferenças físicas e comportamentais (SIMÕES E BISPO, 2006). Sendo assim, é preciso estudar os comportamentos desses usuários em relação a sua interação com o entorno e a mobilidade urbana, para que os projetos sejam mais inclusivos.

Em estudos nessa temática, é comum a citação do conceito de Wayfinding. Esse termo se refere a um processo cognitivo e comportamental que envolve o reconhecimento da posição do indivíduo dentro de um ambiente, sua origem e destino, a localização relativa entre os elementos do entorno, a definição dos deslocamentos e a tomada de decisões, com base em Arthur e Passini (1992), Golledge (1999) e Lynch (2010), tidos como autores de referência na área. 


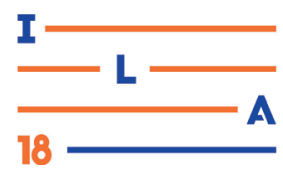

Envolve, portanto, em relação ao usuário, uma conjugação entre suas capacidades perceptivascognitivas, sensoriais e motoras, compreendendo o modo que este processa as informações, a construção de mapas cognitivos, as suas reações frente às condições temporárias ou permanentes do entorno, bem como suas experiências, conhecimentos prévios, referências pessoais, questões estéticas e afetivas.

Em vista disso, torna-se necessário identificar o alcance e a eficiência das metodologias de investigação de comportamento dessas pessoas e assim serem levantadas as suas reais necessidades que poderão guiar futuras pesquisas e projetos para esse público. Uma das aplicações visadas por esse estudo, é o desenvolvimento de Sistemas de Informação, uma vez que o processo de orientação depende essencialmente das condições do fornecimento de informações e das características ambientais, que permitem o reconhecimento da identidade e da função dos espaços pelos indivíduos (DISCHINGER, 2000). A qualidade das informações, portanto, é um dos fatores que afetam o processo de orientação espacial.

Deste modo, o objetivo da presente pesquisa foi realizar um mapeamento quantitativo e qualitativo de metodologias, por meio de uma revisão sistemática da literatura (RSL), e de uma análise de conteúdo com a criação de categorias e subcategorias, associando-as aos tipos de resultados que elas conseguiram proporcionar às pesquisas estudadas. As metodologias analisadas foram aquelas utilizadas para análise de comportamentos das PcD no contexto de Wayfinding em uma etapa pré-design, ou seja, com uma abordagem com foco no usuário, porém antes de serem desenvolvidos projetos e soluções.

Como objetivos específicos, pretendeu-se com o estudo: Levantar os métodos e técnicas utilizados; identificar os tipos de resultados que eles propõem e por fim avaliá-los quantitativamente e qualitativamente, determinando quais deles são mais utilizados em relação aos tipos de dados almejados pelas pesquisas.

Mediante isso, o artigo dá prosseguimento com um entendimento das relações entre deficiência, acessibilidade e wayfinding no contexto de espaços públicos. Em seguida, é descrita a metodologia utilizada. Por fim, são apresentados e discutidos os resultados, com as considerações finais concluindo esse estudo.

\section{Deficiência, acessibilidade e wayfinding}

As deficiências, segundo Dischinger, Bins Ely e Piardi (2012) podem ser divididas em: FísicoMotoras (abrangendo capacidades como força, coordenação motora, precisão, e mobilidade espacial), Sensoriais (envolvendo sistemas de percepção como visão e audição); Cognitivas (relacionando-se com os processos de compreensão, tratamento de informações recebidas, aprendizagem e aplicação dos conhecimentos); e Múltiplas com a combinação de mais de um tipo. No Brasil cerca de $23,92 \%$ da população possui algum tipo de deficiência, sendo a visual a mais predominante com $18,7 \%$, seguida da motora com $6,9 \%$, auditiva com $5 \%$ e intelectual 1,3\% (IBGE, 2010). Sendo assim, as deficiências sensoriais e físico-motoras são as mais comuns.

Além das deficiências e da mobilidade reduzida de caráter permanente, existem as limitações temporárias as quais as pessoas estão sujeitas em algum momento ou fase de suas vidas. Circunstâncias do dia-a-dia, condições individuais e problemas na interação do meio físico, são fatores adicionais que afetam as condições da mobilidade $\mathrm{e}$ de orientação espacial (DISCHINGER; BINS ELY; PIARDI, 2012; SIMÕES E BISPO, 2006). No entanto, os espaços públicos, em sua maioria, não possuem condições adequadas de acessibilidade e, portanto, não estão preparados para abranger a diversidade humana e as inúmeras questões envolvidas em relação à mobilidade e à utilização destes.

Embora muito se tenha a fazer em relação a isso, a questão da acessibilidade tem sido amplamente discutida nos dias atuais. De acordo com a Lei 10.098, ela é definida como:

[...] possibilidade e condição de alcance para utilização, com segurança e autonomia, de espaços, mobiliários, equipamentos urbanos, edificações, transportes, informação e comunicação, inclusive seus sistemas e tecnologias, bem como de outros serviços e instalações abertos ao público, de uso público ou privados de uso coletivo, tanto na zona urbana como na rural, por pessoa com deficiência ou com mobilidade reduzida (BRASIL, 2000, art. $2^{\circ}$ ). 


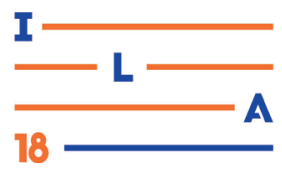

O conceito mencionado resolve que todas as pessoas tenham o direito de acessar qualquer espaço público e equipamento urbano, independentemente de suas limitações, sendo que são os produtos e ambientes que têm de estar preparados para atendê-las (CARVALHO, 2015). Isso é decorrente a uma mudança no modo da sociedade encarar as pessoas com deficiência. Diferentemente dos modelos antigos, religioso e médico, que as encaravam como culpadas, ou como incapazes, respectivamente, resultando na sua exclusão, tem-se ganhado força o modelo chamado de social. Nele essas pessoas são incluídas dentro do conceito de reconhecimento e celebração da diversidade (SIMÕES E BISPO, 2006). A incapacidade, portanto, não é atributo de uma determinada pessoa, mas um conjunto complexo de condições muitas vezes resultantes do próprio ambiente social (SIMÕES; BISPO, 2006; WHO, 2001).

Mesmo com essa evolução, a acessibilidade no ambiente urbano, ainda é uma meta complexa de ser alcançada em sua plenitude, juntamente com a tarefa de se conciliar todas as necessidades sem prejuízo a nenhum grupo, devido às grandes diferenças individuais, os diversos tipos e graus de deficiências, e a dependência de políticas públicas (DISCHINGER, 2000; DISCHINGER; BINS ELY; PIARDI, 2012; LANZONI; SCARIOT; SPINILLO, 2011; SIMÕES E BISPO, 2006). Soma-se a essa complexidade, à necessidade de se considerar tais questões citadas de forma sistêmica, sendo analisadas as inter-relações entre as pessoas, os espaços construídos, o meio e as informações relativas a esses ambientes, tornando-se necessário o estudo das metodologias para esse fim.

Como para o wayfinding é vital o entendimento e a boa interação com o entorno, além de ser necessário a capacidade dos ambientes de conseguirem prover boas condições de navegabilidade espacial, a informação possui uma relevância ainda maior no processo para as $\mathrm{PcD}$. Por conseguinte, torna-se importante estudos e soluções dentro do Design da Informação, uma área do Design que otimiza a forma como o usuário adquire informação em sistemas de comunicação. Possui, portanto, a função de intermediar o usuário com o entorno, auxiliando ou traduzindo a complexidade existente, com uma interpretação do real, de forma útil, gratificante, eficiente e eficaz (CABRAL E RANGEL, 2014; SANTOS, 2015).
Isso se dá por meio da organização e hierarquização das informações, de maneira que tenham um reconhecimento mais imediato e universal possível, além de consistência, facilidade de compreensão e acessibilidade, facilitando o processo de comunicação (ABATE; KOWALTOWSKI; BERNARDI, 2014; CABRAL E RANGEL, 2014; SHERER E SHERER, 2015).

Compreende assim o oferecimento das informações certas, no tempo certo às pessoas, abordando aspectos sintáticos, semânticos e pragmáticos, envolvendo contextualização, planejamento, produção, interfaces, e otimizando tanto o processo de aquisição da informação, quanto das atividades relacionadas (BELLOTTI E PORTELA, 2016; CABRAL E RANGEL, 2014).

É importante destacar que as aplicações do Design da Informação no contexto de wayfinding vão além do funcional e cognitivo, uma vez que devem ser consideradas também questões como atratividade e permanência dos usuários nos ambientes, potencializando a comunicação dos signos do entorno, da arquitetura e do espaço urbano (CABRAL E RANGEL, 2014; KULAK, 2017; OLIVEIRA, SOUZA, 2014; SANTOS, 2015). Uma dessas aplicações, é o Design de Interação de sistemas de informações relativos ao wayfinding. Através de aplicativos em smartphones e totens interativos, por exemplo, é oferecido ao usuário mais controle e inclusão, favorecendo seus deslocamentos e utilização de espaços.

Por meio da humanização, da conscientização sobre contextos sociais, culturais e históricos, do oferecimento de experiências sensoriais positivas ao usuário e da articulação entre a estética e a informação, pode-se obter discursos mais efetivos, com percepção rápida e entendimento profundo a respeito da imagem ambiental, destacando o que é significativo para o público (KULAK, 2017; OLIVEIRA E SOUZA, 2014). Dessa forma, é possível haver um maior envolvimento e apropriação dos espaços pelos usuários e usos urbanos mais efetivos, seguros e inclusivos (SANTOS, 2015).

\section{Metodologia}

\subsection{Revisão Sistemática da Literatura}

Levando em consideração a dispersão de estudos a respeito dos objetos analisados, o presente artigo 


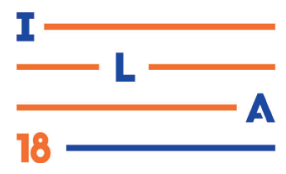

procurou contribuir com sua sistematização por meio de revisão sistemática da literatura (RSL). Esse estudo teve como relevância, guiar futuras pesquisas, com a abordagem com foco no usuário, sobre a mobilidade urbana para pessoas com deficiência. Optou-se por essa metodologia, por reduzir ao máximo os vieses da pesquisa e possibilitar uma análise mais objetiva e sistematizada dos resultados, facilitando uma síntese conclusiva sobre o assunto (SAMPAIO E MANCINI, 2007).

A abordagem desta investigação bibliográfica foi descritiva e exploratória utilizando-se como critérios de inclusão:

- Pesquisas realizadas no Brasil - visando uma aproximação da realidade cultural do país;

- Estudos empíricos que analisam comportamentos de usuários em uma etapa prédesign, ou seja, com entendimento primeiro das suas necessidades, para posteriormente elaborar diretrizes que guiarão uma próxima etapa da geração de soluções. Foram excluídos aqueles com foco no desenvolvimento e avaliação de protótipos e intervenções ergonômicas;

- Estudos com foco principal nas pessoas com deficiência, para que fossem levantadas quais as técnicas são mais efetivas em avaliar as necessidades desse público.

Foram dispensados da análise: artigos de revisão da literatura; estudos que não tinham foco no público mencionado ou que não tratavam de comportamentos de usuários; pesquisas que focavam em políticas públicas urbanas, questões médicas, de exclusão social e de desenvolvimento de produtos e soluções.

Definidos os critérios, foi realizada uma busca no portal Google Acadêmico, filtrando-se por artigos no período entre 2008 a 2018, compreendendo resultados presentes tanto em periódicos científicos quanto em anais de eventos. Utilizou-se para essas buscas os seguintes termos: Wayfinding, reconhecimento do ambiente (ou ambiental, espacial), deslocamento espacial, orientação espacial, combinados com pessoa com deficiência (ou deficiente, termo ainda utilizado em algumas pesquisas).

Foram encontrados 686 artigos. Após uma primeira seleção, a partir da leitura dos títulos, resumos e palavras-chave com uma posterior leitura flutuante nas seções de metodologia, análise de resultados e conclusões, foram identificados e analisados 25 artigos, conforme descrito na próxima seção.

\subsection{Análise de conteúdo}

O estudo dos 25 artigos mencionados se baseou em conceitos da análise de conteúdo descrito por Bardin (2009). Segundo a autora, a metodologia consiste em um conjunto de técnicas de análise das comunicações que se utiliza de procedimentos sistemáticos e objetivos de descrição dos conteúdos das mensagens. A partir disso, é feito a inferência de conhecimentos para o estabelecimento de sentidos e significados.

Utilizou-se princípios dessa metodologia, por esta permitir a sistematização do conteúdo, especialmente no que tange à criação de categorias e índices e as respectivas frequências, o que serviu de base para identificar quais são os tipos de resultados levantados pelos artigos e associá-los aos métodos e técnicas de forma quantitativa e qualitativa. Sob títulos genéricos, a classificação dos elementos em categorias, permite a investigação do que cada um deles tem em comum uns com os outros. Dessa forma pretendeu-se identificar para quais situações tais técnicas são mais utilizadas, e assim fazer inferências de quando são eficientes. A análise, de acordo com a metodologia, foi organizada baseada em três polos iterativos: (1) Pré-análise; (2) Exploração do material; e (3) Tratamento de resultados.

Na primeira, a partir dos documentos selecionados na RSL, foi feito a leitura flutuante com o foco nas seções de metodologia, análise de resultados e conclusões, quando se realizou o primeiro contato com o material para se obter as primeiras impressões e orientações, o que foi útil para a elaboração dos primeiros indicadores e da forma de se organizar e sistematizar o material. Sendo assim, criou-se duas classes de categorias provisórias, a primeira relacionada aos tipos de resultados obtidos e a segunda, às técnicas dessas pesquisas. Essas classes foram organizadas em uma tabela, sendo que as linhas correspondiam à primeira classe de categorias e as colunas à segunda. Também foi criada uma planilha organizando os artigos por nome, resumo, palavras-chave, metodologia e os tipos de deficiência que os estudos abordavam.

Na segunda fase, na exploração do material, à medida que os artigos eram examinados, eles foram 


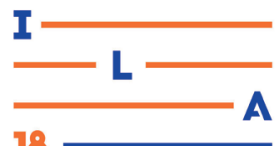

então enquadrados nessas categorias, ou caso não houvesse correspondência e fosse encontrado um novo tipo de resultado ou uma nova técnica, foram criadas novas categorias. Após o enquadramento dos artigos, os tipos de resultados foram agrupados em categorias maiores como na figura 1 :

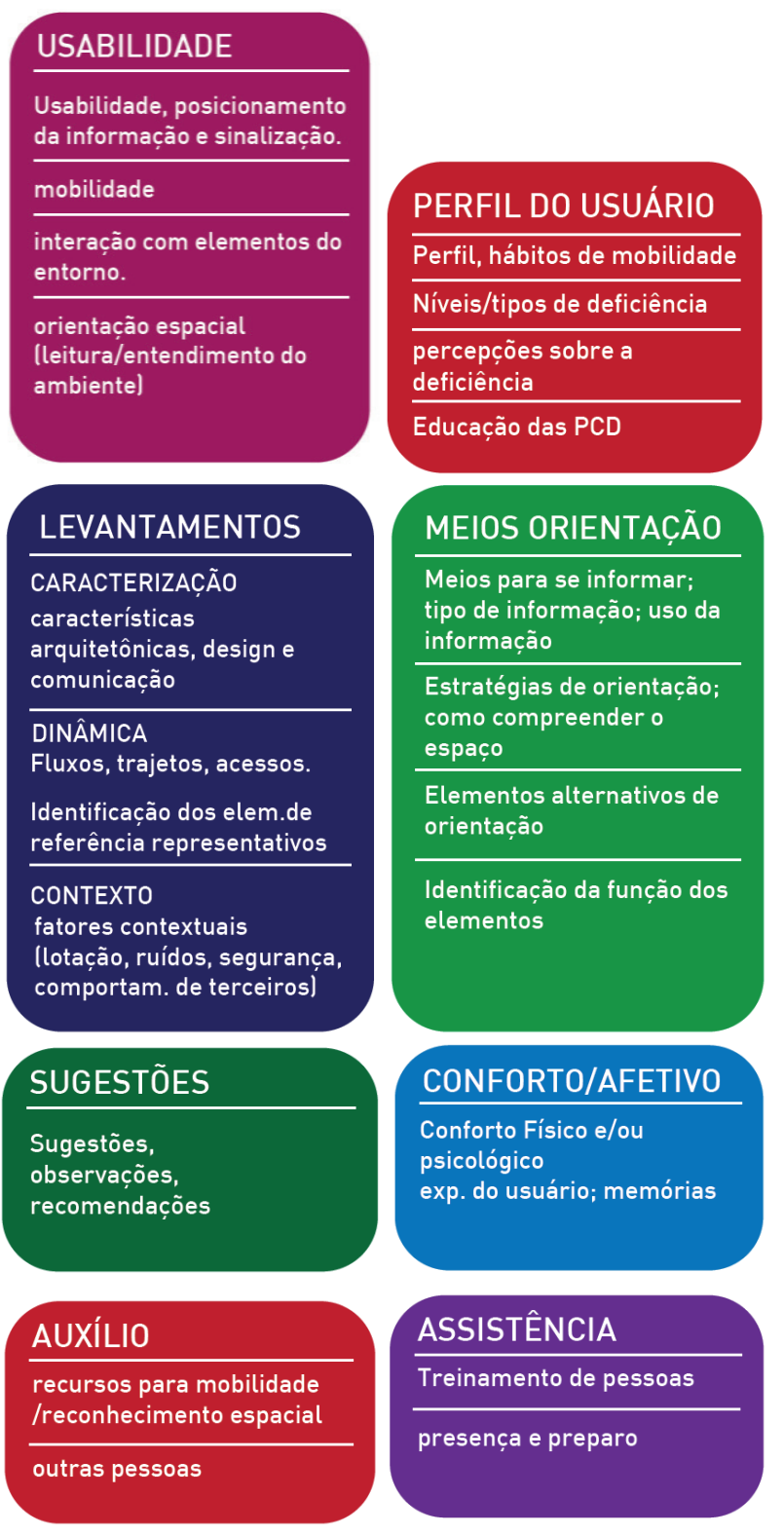

Fig 1 - Categorias e subcategorias - Análise de conteúdo dos artigos. Fonte: os autores.

Por fim na terceira fase, os resultados foram quantificados, permitindo-se chegar no objetivo desse estudo, quando foram feitas inferências sobre a utilização dessas técnicas.

\section{Resultados}

Após o tratamento dos resultados, conforme descrito nos procedimentos metodológicos, chegou-se a tabela 1:

\begin{tabular}{|c|c|c|c|c|c|c|c|c|}
\hline & & \multicolumn{7}{|c|}{ Métodos e Técnicas } \\
\hline & & 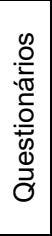 & 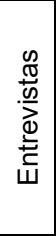 & 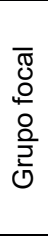 & 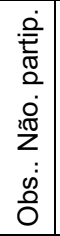 & 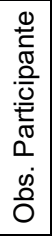 & $\begin{array}{l}\dot{\rho} \\
\bar{\varepsilon} \\
\dot{0} \\
\dot{\alpha} \\
\dot{0} \\
\dot{0} \\
0 \\
0 \\
0 \\
0\end{array}$ & 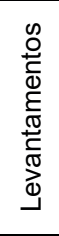 \\
\hline \multirow{10}{*}{ 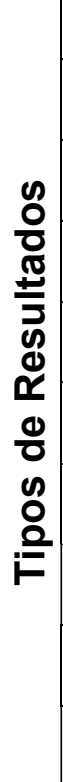 } & Perfil do Usuário & 7 & 6 & 3 & 1 & & 6 & 1 \\
\hline & Sugestões & 2 & 5 & 3 & & 1 & 7 & 3 \\
\hline & $\begin{array}{l}\text { Conforto/ Exp. } \\
\text { Usuário }\end{array}$ & 3 & 1 & 2 & & 1 & 2 & 2 \\
\hline & $\begin{array}{l}\text { Meios de } \\
\text { Orientação }\end{array}$ & 3 & 3 & 4 & 2 & 1 & 9 & 5 \\
\hline & $\begin{array}{l}\text { Facilidades/ } \\
\text { Dificuldades }\end{array}$ & 5 & 8 & 5 & 2 & 2 & 16 & 10 \\
\hline & $\begin{array}{l}\text { Auxílio à } \\
\text { locomoção }\end{array}$ & 1 & 2 & 3 & 2 & & 10 & \\
\hline & $\begin{array}{c}\text { Assistentes de } \\
\text { PCD }\end{array}$ & & 4 & 2 & & & 4 & 1 \\
\hline & $\begin{array}{l}\text { Levantamento } \\
\text { Caraterísticas }\end{array}$ & & 3 & 3 & & 1 & 9 & 8 \\
\hline & $\begin{array}{l}\text { Levantamento } \\
\text { asp. dinâmicos }\end{array}$ & 3 & & 1 & 1 & 1 & 3 & 4 \\
\hline & $\begin{array}{l}\text { Levantamento } \\
\text { asp. efêmeros }\end{array}$ & 1 & 3 & 3 & & & 3 & \\
\hline
\end{tabular}

Tab.1 - Métodos e Técnicas x Tipo de Resultados - Os números se referem a quantidade de pesquisas. Fonte: os autores.

Ao visualizar a tabela 1 , nota-se uma concentração de pesquisas que tiveram como resultados, questões ligadas à análise de usabilidade, facilidades e dificuldades, em especial através dos questionários, entrevistas, grupos focais, passeios acompanhados e levantamentos.

Entretanto, questões relativas ao conforto físico e psicológico, experiência do usuário, bem como a assistência às $\mathrm{PcD}$, o levantamento de características dinâmicas (como fluxos, modo que as pessoas acessam os locais e a identificação de elementos de referência ambientais), e de questões efêmeras ou contextuais (como o excesso de pessoas no local, ruídos, influência da segurança pública e do comportamento de terceiros), foram pouco 


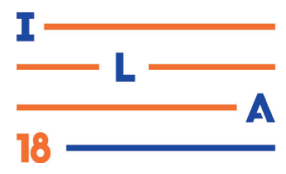

abordadas. A pesquisa de Bins Ely et al., (2016), foi uma das que abordaram essas questões pouco exploradas pelos outros estudos. Nesse caso, entende-se que foram tipos de abordagens ainda pouco exploradas, não sendo possível inferir com clareza, através dessa análise, quais técnicas seriam as mais utilizadas para cada caso.

Em relação aos métodos e técnicas, observa-se que o mais abrangente, o que levantou resultados mais aprofundados, bem como o mais utilizado para levantar grande parte dos dados obtidos pelas pesquisas, foi o Passeio Acompanhado. O método foi desenvolvido por Dischinger (2000) e consiste em um misto de observação e entrevista, com o objetivo de identificar a percepção do espaço pelo usuário, dentro de um percurso que deve ter ponto de partida e objetivos a se alcançar. Nele, o pesquisador deve se limitar a somente acompanhar o usuário e observar o comportamento, podendo realizar entrevistas sobre quais informações são relevantes para o entendimento do espaço e questionamentos acerca de tomadas de decisões, sem conduzi-lo ou ajudá-lo. O usuário por sua vez, deve verbalizar as facilidades e dificuldades identificadas. As conversas são gravadas, os pontos relevantes são descritos, fotografados e localizados em mapas sintéticos dos percursos. São analisadas tanto as questões ligadas aos deslocamentos e à orientação espacial, quanto a realização de algumas tarefas como Andrade e Bins Ely (2014)

apresentam.

Similar a esse método, Baptista e Bernardi (2016) se basearam nos conceitos da Observação Incorporada de Rheingantz (2009). A diferença do passeio acompanhado para essa, é que em uma primeira etapa o pesquisador apenas observa, e na outra, este pode entrevistar o participante durante a observação. $\mathrm{Na}$ pesquisa mencionada adotou-se o primeiro procedimento no trajeto de ida e o segundo, na volta.

Outra variante do método, foi a chamada Observação Não-Estruturada, descrita por Abate e Kowaltowski (2017). Nela os pesquisadores para identificarem o comportamento das crianças com deficiência, acompanharam os seus deslocamentos em uma instituição, porém de modo que elas não os percebessem, eliminando quaisquer interferências que por ventura poderiam ocorrer.

Ainda tratando de Passeio Acompanhado, de acordo com essa revisão, a maioria das pesquisas utilizaram o método para investigar questões relativas às pessoas com deficiência visual. No entanto, artigos como o de Andrade e Bins Ely (2014), Costa e Scarano (2014), Andrade et al. (2015), Zanchin et al. (2011), o aplicaram também para outros públicos, como idosos, pessoas com deficiência física, auditiva e até mesmo para estrangeiros, mostrando que sua eficiência e o tipo de resultados que ele levanta independem de qual limitação os participantes possuíam. Observou-se também que esse método foi o que se obteve mais dados qualitativos. A maioria dos resultados levantados, se concentrou nas questões das percepções acerca das dificuldades e facilidades desses usuários, em especial à mobilidade e realização de tarefas e à interação com o entorno e ambiente. Andrade e Bins Ely (2012), Milaneze et al. (2012), Zanchin et al. (2011), por sua vez identificaram questões sobre a informação, e as respectivas facilidades e dificuldades de se obter, entender, ler e visualizar. Já, Duarte, Medeiros e Lima (2015), Maia e Spinillo (2014) e Silveira e Dischinger (2016) abordaram as dificuldades em relação à orientação espacial e entendimento do ambiente. Andrade e Bins Ely (2014), David, Antunes e Gurgel (2009) e Andrade et al. (2015) conseguiram levantar as duas coisas.

Em seguida observou-se também que foram encontrados resultados consideráveis a respeito dos meios que as pessoas se orientam e se informam, questões sobre o auxílio à locomoção e o levantamento de características do entorno. Algo relevante levantado como estratégias de wayfinding, foi a identificação de elementos alternativos de orientação, como cheiros, movimentação do ar, sombras sonoras, sensações térmicas, sons característicos do ambiente, concentrações de pessoas e estímulos ambientais, conforme as pesquisas de Andrade e Bins Ely (2014), Andrade et al. (2015), David, Antunes e Gurgel (2009), Queiroz e Ono (2015), Silveira e Dischinger (2016). Pode-se inferir com isso, que o método se torna um meio eficiente para o levantamento de questões anteriormente desconhecidas, que possivelmente não seriam identificadas tão facilmente pelas outras técnicas. Por último, verifica-se também a sua relevância em obter dados em relação ao perfil dos participantes, à assistência às pessoas com deficiência e às sugestões dos usuários.

Outra técnica bastante citada que também abrangeu a maioria dos tipos de resultados, foi o grupo focal. Tal técnica consiste em uma discussão direcionada 
em grupo onde um moderador leva os participantes através de perguntas em um tópico específico, chegando-se a certos consensos. Concentra-se em descobrir dos participantes sentimentos, atitudes, e ideias sobre o tema, ou opiniões e comentários sobre um produto (IIDA, 2005). Em geral tal técnica usualmente é feita de modo presencial. No entanto Silveira e Dischinger (2016), e Silveira e Dischinger (2017), a utilizaram de forma on-line, com a vantagem de reunir pessoas de várias regiões do país e consequentemente a identificação de comportamentos em contextos diferentes.

Os destaques da técnica foram as discussões sobre as questões relativas às estratégias de informação e orientação, e das percepções acerca de usabilidade, facilidades e dificuldades, como Andrade e Bins Ely (2014), Bins Ely e Silva (2009), Queiroz e Ono (2015), Silveira e Dischinger (2016), Silveira e Dischinger (2017). Embora apenas a pesquisa de Silveira e Dischinger (2016) identificou com a técnica as percepções dos participantes sobre a própria deficiência, bem como sobre suas próprias capacidades, esse tipo de resultado de fato se mostra relevante em ser explorado para o estudo dos comportamentos e, portanto, outros grupos de foco poderiam ser direcionados para levantar tal questão.

Em comparação com as entrevistas, as duas técnicas apontam tipos de dados semelhantes, no entanto, o Grupo Focal, permitiu debates, consensos, complementação de ideias e levantamento de informações que não ocorreriam individualmente. Sua desvantagem é que nem sempre é possível reunir todos os participantes desejados, como ocorreu na pesquisa de Bins Ely e Silva (2009), onde foi preciso complementar, com a entrevistas em momentos distintos, com duas pessoas com deficiência visual.

Em relação aos questionários e entrevistas, em praticamente todas as pesquisas se mostraram como técnicas complementares, tendo destaque na investigação acerca do perfil do usuário. As entrevistas em sua maioria foram dirigidas às pessoas com deficiência como Baptista e Bernardi (2016), Barroso e Lay (2013), Barroso e Lay (2014), Cunha e Fonseca (2011), Dias e Santos (2016), Zanuncio, Vilela e Mafra (2011), mas também a especialistas (arquitetos, psicólogos, etc.), como em Abate e Kowaltowski (2017), Barbosa e Ornstein (2014) e a pessoas responsáveis por assistir ou auxiliar o primeiro grupo (cuidadores, instrutores, etc.), como Milaneze et al. (2012). As entrevistas sob os diferentes pontos de vistas, dos próprios usuários, especialistas e pessoas que prestam assistência, permitiram um entendimento mais completo das necessidades, mas também, informações importantes sobre como planejar os experimentos.

Em tempo, algo em comum que se conseguiu com os três tipos de técnicas descritas (Passeio Acompanhado, grupos focais e entrevistas), foram as sugestões dos usuários, como Andrade e Bins Ely (2012), Andrade e Bins Ely (2014), Barbosa e Ornstein (2014), Barroso e Lay (2013), Bins Ely e Silva (2009), Braga, Lohmann, Pozzo (2013), Costa e Scarano (2014), Duarte, Medeiros e Lima(2015), Andrade et al. (2015), e Queiroz e Ono (2015) apontam.

Por fim as técnicas classificadas como levantamentos, como índice de visibilidade, combinado com visitas exploratórias em Andrade e Bins Ely (2014), a matriz de acessibilidade em Barbosa e Ornstein (2014) e Duarte, Medeiros e Lima(2015), e walktrought em Braga, Lohmann, Pozzo, (2013) e Costa e Scarano (2014), também atuaram em conjunto com outros procedimentos. Possuindo uma natureza ora exploratória, ora descritiva, essas pesquisas evidenciaram a importância de se fazer um registro prévio como uma importante forma de preparação das demais técnicas, mas também com uma análise crítica do próprio pesquisador.

A primeira - índice de visibilidade- consiste em um método que busca indicar a facilidade para orientarse espacialmente em um terminal a partir de uma abordagem quantitativa, através de uma relação entre o número de linhas de visão existentes e o número total de linhas que deveriam estar disponíveis, em uma rede de nós, ou seja, os centros de atividade onde as instalações estão localizadas como, balcões, acessos, sanitários, lanchonetes, etc. O método pode ser feito observando-se uma planta, mas o mais recomendável é uma visita exploratória, na qual o pesquisador observa preliminarmente essas condições no próprio local (ANDRADE E BINS ELY, 2014).

A segunda - matriz de acessibilidade - é uma tabela onde se registra de forma ordenada os dados coletados na pesquisa, sendo avaliados elementos de wayfinding em relação à acessibilidade. Duarte, Medeiros e Lima (2015), ainda utilizam a matriz de descobertas, em que os dados levantados na 


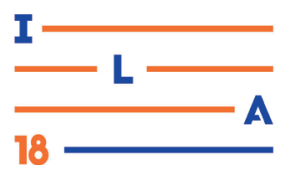

pesquisa são colocados em uma planta com os pontos correspondentes de onde se referem.

Já a terceira - Walktrought consiste em uma visita dos avaliadores aos ambientes de estudo, acompanhados de usuários, como forma de uma compreensão inicial e abrangente do desempenho de um local, sendo levantadas observações dos pesquisadores, mas também comentários dos usuários (BRAGA; LOHMANN; POZZO, 2013; MACHADO ET AL., 2008).

Paralelo à identificação da metodologia e sua relação com os tipos de resultados alcançados, foram identificados também materiais e procedimentos utilizados como auxílio aos métodos e técnicas apresentadas. Pode-se destacar a tomada de vídeos, fotografias gravações de áudios, e o uso de mapas e plantas, destinados aos mapas mentais como Barroso e Lay (2016) e também para fazer marcações de percursos e observações, como por exemplo, no Passeio Acompanhado. Outro recurso interessante foi a matriz de avaliação, descrita em pesquisas como Andrade e Bins Ely (2010), Barbosa e Ornstein (2014), que complementou as demais técnicas utilizadas com uma análise das condições do local pelos próprios pesquisadores. Por fim podese ainda citar Andrade e Bins Ely (2014) e Bins Ely e Silva (2009), que utilizaram um jogo de imagens nos grupos focais, para auxiliar e provocar a discussão.

Embora a revisão da literatura teve como objetivo os mais variados tipos de deficiência e limitações, os resultados não foram tão abrangentes quanto aos tipos de deficiências. Nas pesquisas o tipo mais estudado foi a visual (com 16 artigos), seguida da físico-motora (6 artigos), mobilidade reduzida (3) e a auditiva (2). Acredita-se que possa se ter relação com os dados do IBGE (2010), mostrados na seção 2 , onde se apresenta como as mais frequentes a deficiência visual, seguidas pela físico-motora na população brasileira. Não foram encontradas na presente pesquisa estudos sobre outras deficiências, como a intelectual.

\section{Considerações fïnais}

Com essa revisão da literatura, puderam assim ser mapeadas as técnicas que são mais utilizadas e abrangentes, para o levantamento dos resultados nos estudos relacionadas ao wayfinding das $\mathrm{PcD}$, favorecendo o entendimento das aplicações das mesmas. Embora tenha sido possível observar o que cada uma apresentou, na maioria dos estudos os resultados não ocorreram a partir de uma técnica isoladamente, mas sim por meio de uma análise em conjunto de toda metodologia utilizada, ou seja, o uso de técnicas associadas.

Pretendeu-se com esse tipo de mapeamento, obter uma noção do alcance dos resultados de cada método e técnica, para que possa servir como um auxílio para a escolha daquelas que se encaixam melhor aos objetivos das futuras pesquisas referentes às $\mathrm{PcD}$. Tais resultados obtidos por essa RSL não devem ser considerados universais, uma vez que se basearam em estudos que tratam da realidade brasileira.

Mesmo com toda complexidade dos estudos relacionados à acessibilidade, pode-se afirmar que técnicas como Passeio Acompanhado, Grupo Focal e Entrevistas, conseguiram prover nas pesquisas analisadas, um entendimento detalhado dos comportamentos das PcD relativos ao Wayfinding. No entanto são necessárias para sua efetividade outros procedimentos, que auxiliem e complementem no planejamento e preparação dos experimentos e permitam a análise crítica do pesquisador, tais como técnicas de levantamentos preliminares, como Walktrought. Defende-se que, uma vez sintonizadas as técnicas às etapas metodológicas adequadas, se obterá resultados eficientes com relação as necessidades das pessoas com deficiência, que por sua vez, servirão de subsídio, para o desenvolvimento de projetos realmente inclusivos.

\section{Referências}

ABATE, T. P.; KOWALTOWSKI, D. C. C. K. Avaliação de pisos táteis como elemento de wayfinding em escola de ensino especial para crianças com deficiência visual. Ambiente construído [online], Porto Alegre, vol.17, n.2, pp.53-71, 2017.

ANDRADE, I. F.; ANDRÉIA, M. S.; ZANCHIN, M.; RODEGHIERO NETO, I. Análise das condições de orientação espacial de terminal de embarque aeroportuário sob o ponto de vista dos usuários. In: XV Congresso Internacional de Ergonomia e Usabilidade de Interfaces Humanotecnologia, 2015, Recife. Anais...São Paulo: Blücher, 2015. p. 212. 


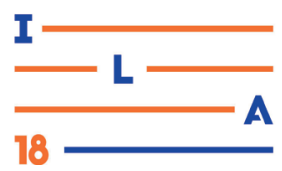

ANDRADE, I. F. ; BINS ELY, V. M.

Acessibilidade em edificações históricas: avaliando o caso de Pelotas. Ação Ergonômica: Revista Brasileira de Ergonomia, Florianópolis, V. 5, n 2. 2010.

Edificações históricas preservadas: intervir para torná-las acessíveis. Revista Ação Ergonômica: Revista Brasileira de Ergonomia, Florianópolis, v. 7, n 2.p.76-91. 2012.

. Orientação espacial em terminal aeroportuário: diferentes perspectivas. In: III Encontro da Associação Nacional de Pesquisa e Pós-Graduação em Arquitetura e Urbanismo - III ENANPARQ, 2014. São Paulo. Anais eletrônicos... São Paulo: Universidade Presbiteriana Mackenzie e Pontifícia Universidade Católica, 2014.

ARTHUR, P. e PASSINI, R. Wayfinding-People, Signs, and Architecture. New York: McGraw-Hill, [1992], 2002.

ABATE, T. ; KOWALTOWSKI, D. C. C. K. ; BERNARDI, N. . Gestão de riscos em projetos de avaliação pós-ocupação (APO). In: XV Encontro Nacional de Tecnologia do Ambiente Construído, 2014, Maceió. Anais... Maceió: Marketing Aumentado, 2014. p. 1167-1176.

BARDIN, L. Análise de Conteúdo. Lisboa, Portugal; Edições 70, LDA, 2009.

BAPTISTA, M. B.; BERNARDI, N. O deficiente visual e o espaço urbano - compreendendo os atributos de apropriação do ambiente. In: VI Encontro Nacional de Ergonomia do Ambiente Construído \& VII Seminário Brasileiro de Acessibilidade Integral, 2016, Recife. Anais... São Paulo: Blücher, 2016, p. 493-504.

BARBOSA, M.B.; ORNSTEIN, S. W. Wayfinding e acessibilidade para pessoas com deficiência visual em sistemas metroviários. In: III Encontro da Associação Nacional de Pesquisa e Pós-Graduação em Arquitetura e Urbanismo, 2014, São Paulo.

Anais... São Paulo: Universidade Presbiteriana Mackenzie e Pontifícia Universidade Católica, 2014. v. 1. p. 1-14.

BARROSO, C. P.; LAY, M. C. D. A influência da orientação espacial na percepção de conforto para a acessibilidade em espaços públicos. In: XII ENCAC e VIII ELACAC, 2013, Brasília. Anais... Brasília: ENTAC - UNB, 2013. v. 1. p. 1-10.

. Acessibilidade universal versus orientação espacial em áreas urbanas. In: XV ENTAC: Encontro Nacional de Tecnologia do Ambiente Construído, 2014, Maceió. Anais... Porto Alegre: ANTAC, 2014. v. 1. p. 1-14.

Conforto na acessibilidade do espaço urbano: percepção de usuários com diferentes condições de mobilidade. Arquisur Revista, v. 9, p. 76-89, 2016.

BELlOTTI, M. P. ; PORTELLA, A. A. A importância do wayfinding na formação da imagem do lugar: o caso campus universitários descentralizados. In: IV ENANPARQ - Encontro da Associação Nacional de Pesquisa e Pós-Graduação em Arquitetura e Urbanismo., 2016, Porto Alegre. Anais... Porto Alegre: PROPAR/ UFRGS, 2016.

BINS-ELY, V. H. M.; SILVA, C. S. Unidades habitacionais hoteleiras na ilha de Santa Catarina: um estudo sobre Acessibilidade Espacial. In: XV Congresso Brasileiro de Ergonomia, VI Fórum Brasileiro de Ergonomia e III ABERGO JOVEM III Congresso Brasileiro de Iniciação Científica, 2008, Porto Seguro. Métis. Caxias do Sul: UCS, 2008, v. 1. p. 401-406.

BINS ELY, V. H. M.; PINTO, C. F. M.; FUJIWARA, M.; LISBOA, S.; DORNELES, V. G. Terminal de transporte coletivo acessível. In: VI Encontro Nacional de Ergonomia do Ambiente Construído \& VII Seminário Brasileiro de Acessibilidade Integral, 2016, Recife. Anais... São Paulo: Blucher, 2016. v. 2. p. 65.

BRAGA, G. B. ; LOHMANN, Alberto ; POZZO, R. R. O Projeto Arquitetônico do Espaço Destinado a Pessoas com Deficiências Auditivas e Visuais: Estudo de Caso na Associação de Apoio aos Deficientes Auditivos e Visuais de Campos NovosSC. In: VI PROJETAR - O Projeto como Instrumento para a Materialização da Arquitetura: ensino, pesquisa e prática, 2013, Salvador. Anais... Natal: UFRN, 2013.

BRASIL. Lei $\mathbf{n}^{\mathbf{0}} \mathbf{1 0 . 0 9 8}$ de 19 de Dezembro de 2000. Estabelece normas gerais e critérios básicos para a promoção da acessibilidade das pessoas portadoras de deficiência ou com mobilidade reduzida, e dá outras providências. Diário Oficial 


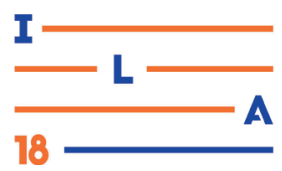

[da República Federativa do Brasil], Brasília.

Disponível em:

$<$ https://www.presidencia.gov.br/ccivil_03/Leis/L10

048.htm>. Acesso em: 10 Jan. 2017.

CABRAL, A.; RANGEL, A. A tipografia urbana na (des)orientação da cidade. In: III Congresso Ergotrip Design: Design, Ergonomia e Interação HumanoComputador, 2014, Natal. Anais... Natal: UFRN, 2014.

CARVAlHO, C. H. R. Políticas de melhoria das condições de acessibilidade no transporte urbano no Brasil. Rio de Janeiro: IPEA, 2015. (Texto para Discussão, n. 2139). Disponível em:

$<$ http://www.ipea.gov.br/portal/images/stories/PDFs /TDs/td_2139.pdf $>$. Acesso em: 25 Jun. 2018.

COSTA, A. D. L.; SCARANO, L. Orientação espacial em Hospital Público Universitário. In: III Encontro da Associação Nacional de Pesquisa e Pós-graduação em Arquitetura e Urbanismo Arquitetura, Cidade e Projeto: uma construção coletiva, 2014, Campinas-SP. Anais... São Paulo: Universidade Presbiteriana Mackenzie, Pontifícia Universidade Católica de Campinas, 2014.

CUNHA, P. V.; FONSECA, L. P. Sistema de sinalização acessível em Braille. Infodesign (SBDI. Online), Rio de Janeiro, v. 8, p. 64-73, 2011.

DAVID, J. S.; ANTUNES, X. M.; GURGEL, V. T. Cidade Acessível: Igualdade de Direitos e Particularidades da pessoa com Deficiência Visual. Mnemosine, Rio de Janeiro, v. 5, p. 80-94, 2009.

DIAS, G. S.; SANTOS, I. M. Criação de um mapa tátil através da tecnologia assistiva: mais acessibilidade aos deficientes visuais com a utilização da impressão $3 \mathrm{~d}$. In: $12^{\circ}$ Congresso Brasileiro de Pesquisa e Desenvolvimento em Design, 2016, Belo Horizonte. Anais... São Paulo: Blucher, 2016.

DISCHINGER, M. Designing for all senses: Accessible spaces for visually impaired citizens. 2000. Tese (Doutorado em Filosofia) - Department of Space and Process School of Architecture, Chalmers University of Technology, Göteberg, Suécia, 2000.

DISCHINGER, M.; BINS ELY, V. H. M.; PIARDI, S. M. D. G. Promovendo Acessibilidade espacial nos edifícios públicos: Programa de Acessibilidade às Pessoas com Deficiência ou Mobilidade Reduzida nas Edificações de Uso Público. Florianópolis: Ministério Público do Estado de Santa Catarina, 2012.

DUARTE, A. B.; MEDEIROS, A. T. F.; LIMA, M. A. A APO como estratégia de investigação com vistas à promoção de ambientes inclusivos em âmbito educacional. In: VII Seminário PROJETAR, 2015, Natal. Anais... Natal: UFRN, 2015.

GOLLEDGE, R. G. Wayfinding Behavior: Cognitive Mapping and Other Spacial Process. Johns Hopkins University Press, EUA, 1999.

IBGE. Censo Demográfico 2010, Brasília: IBGE, 2010.

IIDA, I. Ergonomia: Projeto e Produção. 2. ed. rev. e ampliada. São Paulo: Edgard Blucher, 2005.

KULAK, S. M. O Design Gráfico Ambiental Como Ferramenta da Comunicação Urbana: Estética e Informação nos Ambientes Citadinos. In: XXXX Congresso Brasileiro de Ciências da Comunicação, 2017, Curitiba. Anais... São Paulo: Intercom, 2017.

LYNCH, K. A imagem da cidade. Tradução de Jefferson Luiz Camargo. 2. ed. São Paulo: WWF Martins Fontes, 2010.

LANZONI, C. O.; SCARIOT, C. A.; SPINILLO, C. G. Sistema de informação de transporte público coletivo no Brasil: algumas considerações sobre demanda de informação dos usuários em pontos de parada de ônibus. Infodesign, Rio de Janeiro, v. 8, p. 54-63, 2011.

MACHADO, E. S. ; FLEMING, L. ; SILVA, H. S. ; CAVALCANTI, P. B. ; AZEVEDO, G. A N ; RHEINGANTZ, P. A. . Uma reflexão sobre métodos utilizados em APO: estudo de caso da Creche Edson Luiz. RJ. In: XII Encontro Nacional de Tecnologia do Ambiente Construído - Geração de valor no ambiente construído, inovação e sustentabilidade, 2008, Fortaleza. Anais... Porto Alegre: Antac, 2008. v. 1. p. 1-13.

MAIA, A. F.; SPINILLO, C. G. Como os Daltônicos percebem as Representações Gráficas de Mapas do Transporte Público. In: $6^{\circ}$ Congresso Internacional de Design da Informação, 2013, Recife. Anais... São Paulo: Blucher, 2014, v. 1, n. 2. 


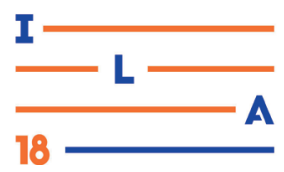

MILANEZE, G. L. S.; GOETTEMS, R. F.; SILVEIRA, C. S.; ELY, V. H. M. B. Usabilidade e deslocamento para acessibilidade no restaurante universitário da UFSC. In: $1^{\circ}$ Simpósio de Integração Científica e Tecnológica do Sul Catarinense, 2012, Criciúma. Revista TécnicoCientífica (IFSC). Florianópolis: IFSC, 2012. v. 3. p. $166-175$.

QUEIROZ, V. M.; ONO, R. Acessibilidade para pessoas com deficiência visual em parques: contribuições à NBR 9050. In: XIII Encontro Nacional de Conforto do Ambiente Construído / IX Encontro Latino-Americano de Conforto no Ambiente Construído, 2015, Campinas. Anais... Porto Alegre: ANTAC, 2015.

OLIVEIRA, M. M.; SOUZA, S. M. R. O caráter multidisciplinar da Comunicação Visual em hospitais. Comunicação \& Inovação (Online), São Caetano do Sul, v. 15, p. 159-170, 2014

RHEINGANTZ, P. A.; AZEVEDO, G. A N; BRASILEIRO, Alice; ALCANTARA, Denise; QUEIROZ, M. Observando a Qualidade do Lugar: procedimentos para a avaliação pósocupação. 1. ed. Rio de Janeiro: Proarq/FAU-UFRJ, 2009. v. 1.117 p.

SAMPAIO, R. F.; MANCINI, M. C. Estudos de Revisão Sistemática: Um Guia para Síntese Criteriosa da Evidência Científica. Revista Brasileira de Fisioterapia, São Carlos, v.11, n.1, p 83-89, jan/fev. 2007

SANTOS, Fátima Aparecida dos. Design de informação e cidade: um exercício embrionário tendo Brasília como cenário. Infodesign (SBDI. Online), Rio de Janeiro, v. 12, p. 157-157, 2015

SILVEIRA, C. S.; DISCHINGER, M. Orientação e mobilidade de pessoas com deficiência visual no transporte público: discussões através de grupo focal nacional. Revista PROJETAR Projeto e Percepção do Ambiente, Natal, v. 2, p. 124, 2017.

Referenciais para orientação e mobilidade de pessoas com deficiência visual no transporte público e coletivo. In: VI Encontro Nacional de Ergonomia do Ambiente Construído \& VII Seminário Brasileiro de Acessibilidade Integral, 2016, Recife. Anais ... São Paulo: Editora Edgard Blücher, 2016. v. 1. p. 205.
SIMÕES, J. F.; BISPO, R. Design Inclusivo: Acessibilidade e Usabilidade em Produtos, Serviços e ambientes. 2a ed. Lisboa: Centro Português de Design, 2006. Disponível em:

$<$ http://designincludesyou.org/wpcontent/uploads/2012/04/Design InclusivoVol1.pdf $>$. Acesso em: 25 Jun. 2017.

SCHERER, F. V.; SCHERER, G. B. Estudo de Método Projetual para Sistema Integrado de Identidade Visual, Design da Informação e Orientação. Infodesign (SBDI. Online), Rio de Janeiro, v. 12, p. 171-193, 2015

\section{WHO. International Classification of} Funcionality, Disability and Health (ICF). Geneva: WHO, 2001. Disponível: $<$ http://www.asphi.it/english/disabilitaoggi/definizio nioms.htm> Acesso em: 25 Jun. 2018.

ZANCHIN, M.; RODEGHIERO NETO, I.; BROMBILLA, D. C.; ANDRADE, I. F. Análise das condições de acessibilidade espacial em shopping center: o caso do shopping pelotas. In: VI Encontro Nacional de Ergonomia do Ambiente Construído \& VII Seminário Brasileiro de Acessibilidade Integral, 2016, Recife. Anais... São Paulo: Blucher, 2016. p. 708.

ZANUNCIO, S. V.; VILELA, J. S.; MAFRA, S. C. T. O mapa tátil como uma ferramenta de auxílio ao deficiente visual: o caso da Universidade Federal de Viçosa/MG. Revista Ingepro: Inovação, Gestão e Produção, Santa Maria, UFSM, v. 03, p. 25-34, 2011. 